\title{
Simplified Boundary Element Method for Kinematic Response of Single Piles in Two-Layer Soil
}

\author{
Fayun Liang, ${ }^{1,2}$ Haibing Chen, ${ }^{1,2}$ and Wei Dong Guo ${ }^{3}$ \\ ${ }^{1}$ Key Laboratory of Geotechnical and Underground Engineering of Ministry of Education, Tongji University, \\ Shanghai 200092, China \\ ${ }^{2}$ Department of Geotechnical Engineering, Tongji University, Shanghai 200092, China \\ ${ }^{3}$ School of Civil Mining and Environmental Engineering, University of Wollongong, Wollongong, NSW 2522, Australia
}

Correspondence should be addressed to Fayun Liang; fyliang@tongji.edu.cn

Received 15 May 2013; Accepted 23 July 2013

Academic Editor: Ga Zhang

Copyright (C) 2013 Fayun Liang et al. This is an open access article distributed under the Creative Commons Attribution License, which permits unrestricted use, distribution, and reproduction in any medium, provided the original work is properly cited.

A simple approach is formulated to predict the elastic, kinematic pile bending during harmonic or transient excitation for a circular pile (rather than a simplified thin strip). The kinematic response of a pile embedded in two-layer soil is resolved in the frequency domain caused by the upward propagation of shear waves from the underlying bedrock. The simplified approach is generally valid to nonhomogeneous soil profiles, in light of the good comparison with the dynamic FE method and BDWF solution. It employs the soil-displacement-influence coefficients $I_{s}$ to consider the pile-soil interaction (resembling the spring constant $k_{x}$ in the BDWF) and provides conservative estimations of maximum kinematic bending moments at the soil-layer interface (with a sharper stiffness contrast). The accuracy of the approach may be improved by incorporating the interaction of soil into the soil-displacementinfluence coefficients $I_{s}$ for such cases with $V_{b} / V_{a}<3$.

\section{Introduction}

Kinematic response is one of the key issues in seismic design of pile foundations [1-4], as the dynamic response of the pile structure largely differs from the response at the free field soil caused by seismic wave. In practice, the influence of inertial loading at the pile-head level has conventionally received sufficient attention by design engineers, but not the kinematic seismic response [5]. The existing earthquake investigations $[6,7]$ and experimental studies $[8]$ demonstrate that at the interface of two-layer soils with a sharp stiffness contrast $[2,3,9,10]$, or at a pile-head with fixed constraints [11, 12], large kinematic bending moments may be induced to inflict damage to the pile. This problem has attracted the attention researchers [13-15] and is highlighted in some advanced seismic codes [16].

The kinematic response in the pile-soil system has been analyzed by considering the effect of the passive pile using rigorous mechanical solutions $[17,18]$, numerical methods [19-25], and some simplified models [2, 3, 26-30]. Rigorous solutions and numerical methods for the kinematic pile bending are, however, not convenient to design purposes. Empirical formulas are developed for evaluating the bending moment at the pile-head or at the interface of two-layer soils $[2,3,11]$. Among them, a Beam-on-Dynamic-WinklerFoundation (BDWF) formulation was used successfully in practice, although it was confined to the harmonic excitation at the pile head. The BDWF (or the Winkler model) is underpinned by a frequency-dependent impedance $\left(=k_{x}+\right.$ $i \omega C_{x}$ ), in which the continuously distributed springs $k_{x}$ ( $\delta E_{s}$ ) is empirically related to a dimensionless coefficient $\delta$ (used for a given pile-soil system, regardless of layers). Accurate selection of the value $\delta$ is not critical to calculating the pile-head deflection but is important to predicting the kinematic bending moment and shear force $[19,31]$. An optimized $\delta$ is thus required to obtain correct kinematic pile bending at the interface of soil layers. On the other hand, a simplified boundary element formulation proposed by Poulos and Davis [32] offers good estimates of bending moment and shear force for static loading. It would be good to 
see its accuracy in predicting the kinematic seismic response of pile, especially at the sharp stiffness contrasts between adjacent soil layers.

In this paper, the simplified approach [32] is employed to evaluate the kinematic pile bending during harmonic or transient excitation, concerning piles in two-layer soil. The pile is modeled as a circular shape rather than a thin strip adopted previously [32], and the soil displacement is given by the Mindlin equation with corresponding elastic modulus. A nodal relative displacement is obtained by onedimensional site response and is then imposed on the pile. The solution was compiled into a program operating in Matlab platform. For some typical cases, a comprehensive study on the kinematic seismic response during harmonic or transient excitation has been carried out, and the results are compared with available dynamic FE method and the BDWF solutions. The study sheds new light on the kinematic bending moment at the interface of two-layer soil and at the pile head and may facilitate the use of the simplified boundary element method to predict the kinematic seismic response of a single pile.

\section{Simplified Analysis Procedure}

2.1. Basic Assumptions for Pile and Soil Model. The onedimensional model for a floating or end-bearing single pile embedded in a two-layer soil is shown in Figure 1. The circle pile is assumed as linearly hysteretic beam having a length $L$, a diameter $d$, a mass density $\rho_{p}$, and a bending stiffness $E_{p} I_{p}$. The pile is discretized into $n+1$ segments of equal lengths $h$, but for a length of $h / 2$ for the top and the tip segments, respectively. Each segment is subjected to a uniformly distributed load $p_{i}$ over the semicircular area. The pile is head restrained (fixed head) or free to rotate (free head), and sits above a bedrock. The linearly hysteretic soil profile is characterized by an upper-layer of thickness $H_{a}$ and a shear wave velocity $V_{a}$, which is underlain by a lower layer of thickness $H_{b}$ and shear wave velocity $V_{b}$. The two layers have damping ratios $\beta_{b}$ and $\beta_{a}$, mass densities $\rho_{b}$ and $\rho_{a}$ and Poisson's ratios $\mu_{a}$ and $\mu_{b}$. A shear wave propagates vertically through the free field soil, which induces the horizontal harmonic motion and horizontal displacements. The motion at the bedrock surface is expressed by the amplitude of either bedrock displacement $U_{g}$ or the bedrock acceleration $\omega^{2} U_{g}$.

2.2. Calculation of the Horizontal Displacement of the Pile. Kinematic response of a single pile is induced by the free-field soil displacement shown in Figure 1. The Mindlin hypothesis does not meet the needs of dynamic analysis. However, the Mindlin equation is still valid for calculating elastic displacement and stress fields caused by a dynamic loading, provided that the characteristic wavelength in the soil is sufficiently long in comparison with the horizontal distance across the zone of major influence [28, 33], as is noted for nonhomogeneous soil by Poulos and Davis [32]. In the current, simplified BEM formulation, the soil displacement $\mathbf{u}_{s}$ (due to the pile-soil interface pressure) is gained using

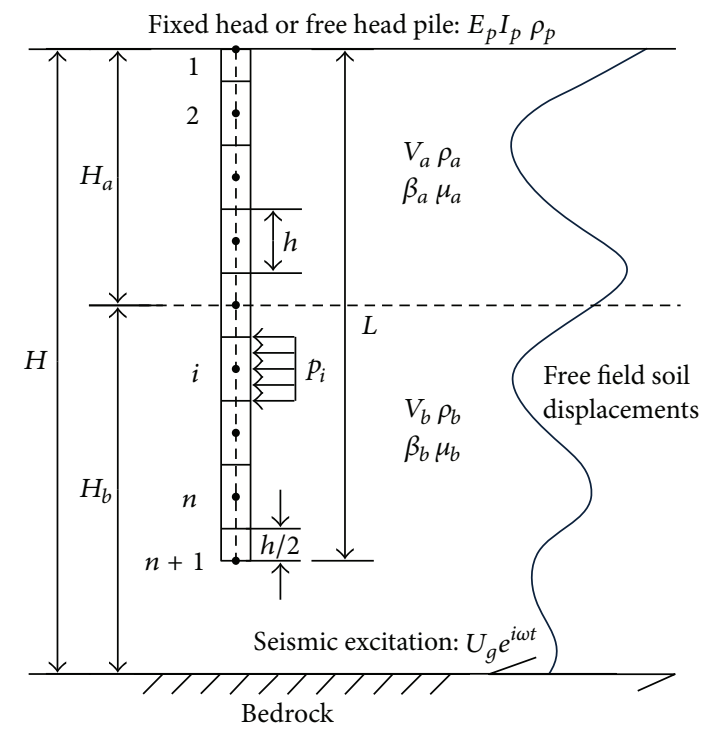

FIGURE 1: Analysis model of a pile in a two layer soil profile subjected to vertically-propagating seismic $\mathrm{SH}$ waves.

the Mindlin solution [34], which is then added together with free-field soil displacement

$$
\mathbf{u}_{s}=\mathbf{I}_{s} \mathbf{p}_{i}+\mathbf{u}_{e},
$$

where $\mathbf{I}_{s}$ is the soil-displacement-influence coefficient; $\mathbf{p}_{i}$ is the vector of soil-pile interface pressure over the semicircular area; and $\mathbf{u}_{e}$ is the free-field soil displacement estimated using one-dimensional site response for vertically propagating shear waves through an unbounded medium [35].

The dynamic equilibrium under steady-state conditions for the pile may be written in the following form using the finite-difference method [28]:

$$
\frac{E_{p} I_{p}}{h^{4}} \mathbf{D} \mathbf{u}_{p}+\mathbf{M} \ddot{\mathbf{u}}_{p}+\mathbf{C}_{x}\left(\dot{\mathbf{u}}_{p}-\dot{\mathbf{u}}_{e}\right)=-d \mathbf{p}_{p}
$$

where $\mathbf{u}_{p}$ is the horizontal displacement of the pile, with the cap "." indicating differentiation with time; $\mathbf{p}_{p}$ is the vector of soil-pile interface pressure; $\mathbf{D}$ is the matrix of finite difference coefficients; $\mathbf{M}$ is the pile mass; and $\mathbf{C}_{x}$ is the soil radiation damping. Here, the soil damping is the same as that of the simplified boundary element model [28], and

$$
C_{x}=5 d \rho_{s} V_{s},
$$

where $V_{s}$ is the shear wave velocity of soil and $\rho_{s}$ is the density of soil.

The displacement compatibility between the pile and the adjacent soil offers $\mathbf{u}_{s}=\mathbf{u}_{p}$. Taking the displacement as $\mathbf{u}_{p}$ and substituting (1) into (2) result in the following:

$$
\frac{\mathbf{I}_{s}}{d}\left[\mathbf{M} \ddot{\mathbf{u}}_{p}+\mathbf{C}_{x} \dot{\mathbf{u}}_{p}+\frac{E_{p} I_{p}}{h^{4}} \mathbf{D} \mathbf{u}_{p}\right]+\mathbf{u}_{p}=\mathbf{u}_{e}+\frac{\mathbf{I}_{s}}{d} \mathbf{C}_{x} \dot{\mathbf{u}}_{e} .
$$

Equation (4), together with the pile-top and -bottom boundary conditions, leads to $n+5$ unknown displacements, which 
involve the pile nodes from 1 to $n+1$ (see Figure 1) and 4 additional nodes at the pile top and tip. Equation (4) is resolved in either frequency or time domain and may attain the required accuracy using 21 segments of the pile [32].

2.3. Soil-Displacement-Influence Coefficients. Poulos and Davis [32] obtained soil-displacement-influence coefficients $\mathbf{I}_{s}$ by integrating the Mindlin equation over a rectangular plane and taking the pile as a thin rectangular vertical strip. Ideally, a circular pile (rather than a thin strip) should be used. In elastic, semi-infinite space, the force $P$ in the horizontal direction at a depth $c$ induces a displacement component $u_{x}$, which at any other point $(x, y, z)$ is given by

$$
u_{x}=\frac{P}{G} f\left(\mu_{s}, x, y, z, c\right),
$$

where $G$ is shear modulus of soil and $\mu_{s}$ is the Poisson ratio.

The coefficients of the proposed method are obtained in two steps: firstly, (5) is integrated over a rectangular area from a depth $c$ of $c_{1}$ to $c_{2}$ and across the pile width from $-d / 2$ to $d / 2$ in Figure 2 which offers

$$
u_{x}\left(\mu_{s}, x, y, z, c, s\right)=\frac{P}{G} \int_{-d / 2}^{d / 2} \int_{\mathcal{C}_{2}}^{c_{1}} f\left(\mu_{s}, x, y-s, z, c\right) d s .
$$

Secondly, (6) is reexpressed in a cylindrical coordinate, which is then integrated over the semi-circular pile surface with respect to the angle $\theta$ (see Figure 2) to gain the horizontal component of the displacement. The soil-displacementinfluence coefficients, taking as weighted average of the integrated horizontal displacements, are deduced as

$$
I_{s}=\frac{P}{G} \int_{0}^{\pi / 2} \int_{-d / 2}^{d / 2} \int_{\mathcal{C}_{2}}^{c_{1}} f\left(\mu_{s}, \frac{d}{2} \cos \theta, \frac{d}{2} \sin \theta-s, z, c\right) \cos \theta d c d s d \theta .
$$

Equation (7) is solved by numerical integration using an adaptive Lobatto rule [36].

2.4. Harmonic Response in the Frequency Domain. Wave produces horizontal harmonic motion in the free field, as shown in Figure 1. This is described by $u(t)=U_{g} e^{i \omega t}$, and the associated free-field horizontal displacement is given by $u(t)=U_{e} e^{i \omega t}$. One-dimensional site response analysis can be formulated as

$$
\rho \frac{\partial^{2} u}{\partial t^{2}}=G \frac{\partial^{2} u}{\partial z^{2}}+\eta \frac{\partial^{3} u}{\partial z^{2} \partial t}
$$

where $\rho$ is the mass density, $\eta$ is viscosity, and $u(z, t)$ is displacement. Equation (8) is resolved in frequency domain analysis [37, 38], allowing the nodal relative displacement to be obtained.

The current dynamic analysis employs time domain analysis and frequency domain analysis [21, 35, 39]. Frequency domain methods are widely used to estimate the dynamic impendences of the pile head. In the strong seismic motions, time domain method (involving the Newton-Raphson iteration and the Newmark method [40]) is used to obtain the nonlinear results. Equation (4) was resolved in time domain [28]. In contrast, to facilitate comparison with the rigorous FE method and BDWF model, (4) is resolved herein in the frequency domain by the following form:

$$
\left[\mathbf{E}+\frac{\mathbf{I}_{s}}{d}\left(\frac{E_{p} I_{p}}{h^{4}} \mathbf{D}-\omega^{2} \mathbf{M}+i \omega \mathbf{C}_{x}\right)\right] \mathbf{U}_{p}=\left(\mathbf{E}+i \omega \frac{\mathbf{I}_{s} \mathbf{C}_{x}}{d}\right) \mathbf{U}_{e},
$$

where $i=\sqrt{-1} ; \omega$ is the excitation frequency; $\mathbf{U}_{p}$ is the amplitude of pile displacement; $\mathbf{U}_{e}$ is the amplitude of addition displacement in the free-field soil; and $\mathbf{E}$ is the identity matrix.

A cut-off method $[28,33]$ is generally used to accommodate soil yield around the pile. If the pressure at the pilesoil interface exceeds the ultimate lateral pressure of soil, the excess pressure is redistributed to other segments through iteration until pressure at all pile nodes within the ultimate values. This study, however, will not consider this yield and will be confined to elastic analysis using the simplified approach for piles in two-layer soil.

\section{Validation of Simplified Method}

3.1. Comparison with Dynamic Finite-Element Solution. The proposed simple approach is compared with dynamic FE results concerning a free head pile embedded in a two-layer soil deposit [19]. The pile-soil model is the same as that shown in Figure 1, except that the pile tip is extended into the underlying bedrock. The pile-soil system is featured by a ratio of soil layer thickness $H_{a} / H_{b}$ of 1 , a soil density $\rho_{a}=\rho_{b}$, a soil Poisson's ratio $\mu_{a}=\mu_{b}=0.4$, and a soil damping coefficient $\beta_{a}=\beta_{b}=10 \%$. The pile has a slenderness ratio $L / d$ of 20 , a pile-to-soil stiffness ratio $E_{p} / E_{a}$ of 5000 , and a pile density $\rho_{p}$ of $1.60 \rho_{a}\left(\rho_{a}=1900 \mathrm{~kg} / \mathrm{m}^{3}\right)$.

A comparison between the simplified approach and FE solution [19] is presented in Figures 3(a) and 3(b), respectively, for the profiles of the pile deflection and bending moment amplitude at the natural frequency of soil deposit $\left(\omega=\omega_{1}\right)$. A good agreement is evident. The current, simplified approach can reveal the kinematic bending moments at the interface of the two layers, despite the $\sim 20 \%$ overestimation of the maximum bending moment (against FE result) of the pile in Case D.

Figure 4 shows the amplitude spectrum of maximum kinematic bending moment as a function of the frequency ratio $\omega / \omega_{1}$. A good agreement is again observed between the simplified approach and the dynamic FE solution [19]. Both indicate that the peak kinematic bending moment occurs at the inherent frequency of the soil.

3.2. Comparison with BDWF Formulation. The proposed approach for kinematic loading along the pile depth during the lateral ground movements is compared with the BDWF solution [19]. The pile-soil system is the same as the case just discussed in the last section. To examine the sensitivity of the parameters, four groups of 12 cases (Table 1) were studied, by maintaining soil density $\rho_{a}=\rho_{b}$, soil Poisson's 


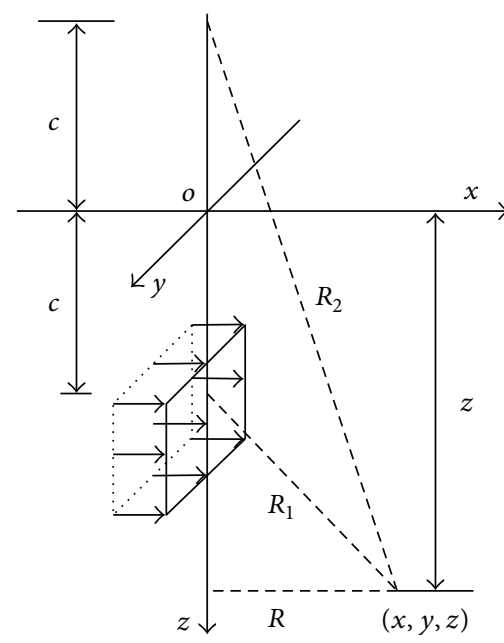

(a) Integrated area

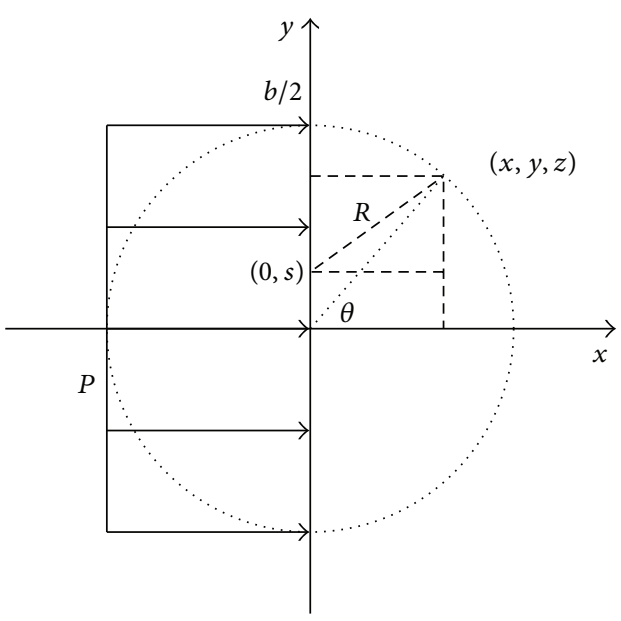

(b) Weighted average area

FIGURE 2: Integrated along the semi-circular pile surface.

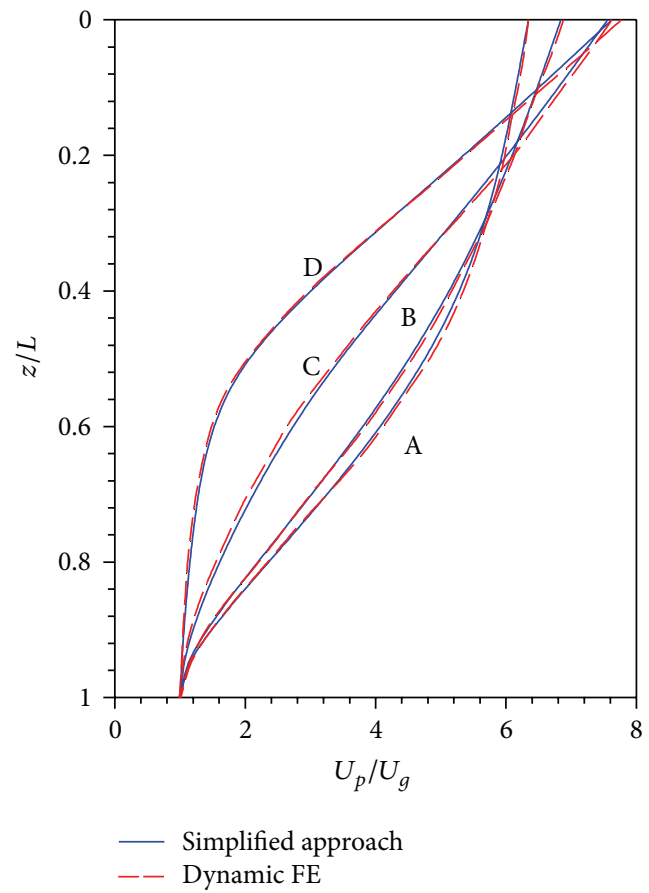

(a) Deflections

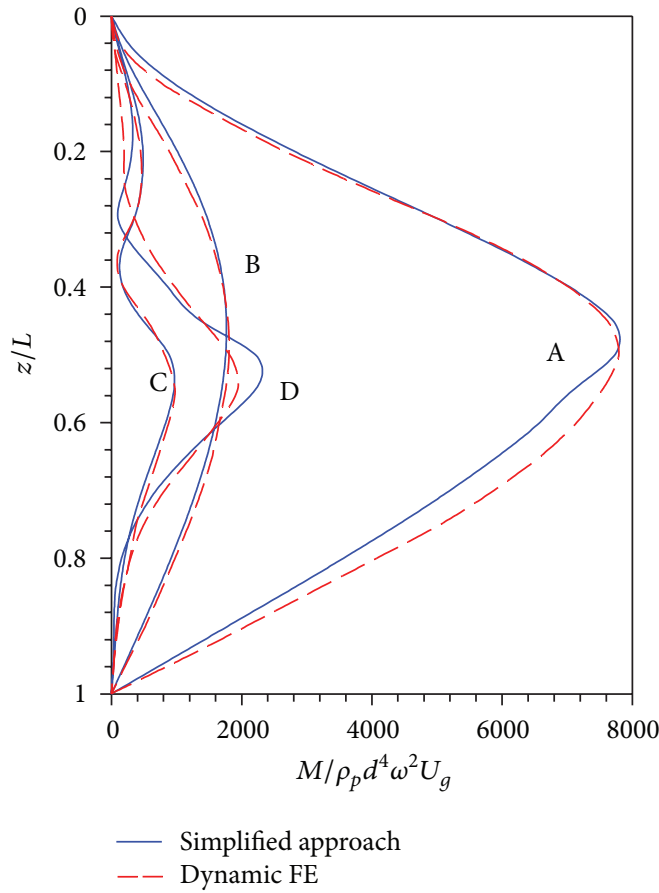

(b) Kinematic bending moment

FIGURE 3: Comparison of amplitude of pile deflections and bending moment between FE solution and simplified method in a two-layer soil (A: $V_{b} / V_{a}=0.58, \mathrm{~B}: V_{b} / V_{a}=1, \mathrm{C}: V_{b} / V_{a}=1.73$, and D: $V_{b} / V_{a}=3$ ).

ratio $\mu_{a}=\mu_{b}=0.4$, soil damping coefficient $\beta_{a}=\beta_{b}=10 \%$, and pile density $\rho_{p}=1.60 \rho_{a}$.

As shown in Table 1, the BDWF method adopts an optimized $\delta$ to obtain kinematic pile bending at the interface of two-layer soil. In contrast, the current method uses the displacement-influence coefficients $\mathbf{I}_{s}$ to consider the pilesoil interaction (resembling the spring constant $k_{x}$ in the Winkler model) and may incorporate the interaction of soil along the pile to improve the accuracy. Nevertheless, when the ratio of the shear wave velocities $V_{b} / V_{a}$ of two soil layers exceeds 3, a larger than 15\% error (compared with the FE method) in maximum kinematic bending moment may be seen using the simplified method. This is discussed next concerning Case 12 for kinematic bending at the two-layer interface and at the pile head (at the natural frequency of soil deposit).

3.2.1. Kinematic Pile Bending. Figure 5 shows the amplitude distributions of kinematic pile bending and shear force from the simplified method and the BDWF solutions. The 


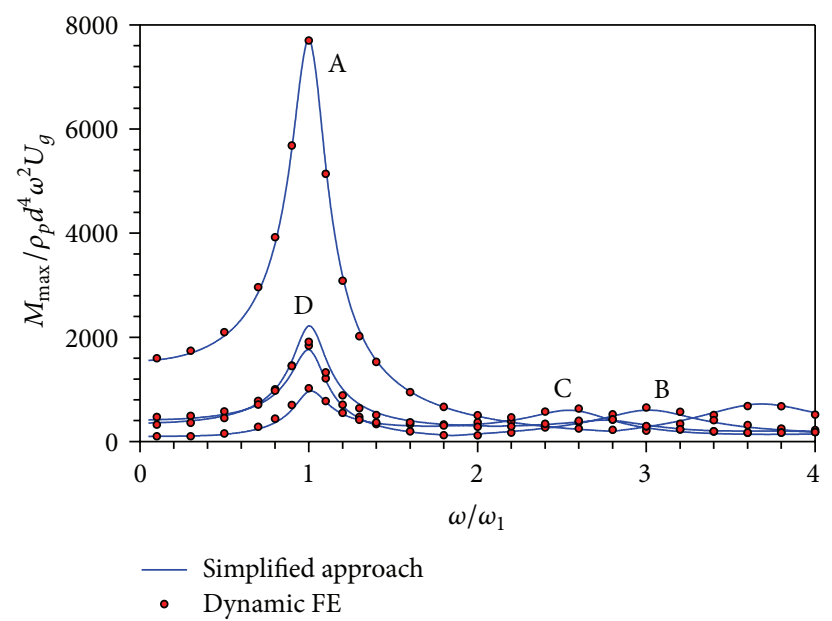

FIGURE 4: Comparison of maximum bending moment amplitude between FE solution and simplified method in a two-layer soil $\left(\mathrm{A}: V_{b} / V_{a}=\right.$ 0.58, B: $V_{b} / V_{a}=1, \mathrm{C}: V_{b} / V_{a}=1.73$, and D: $\left.V_{b} / V_{a}=3\right)$.

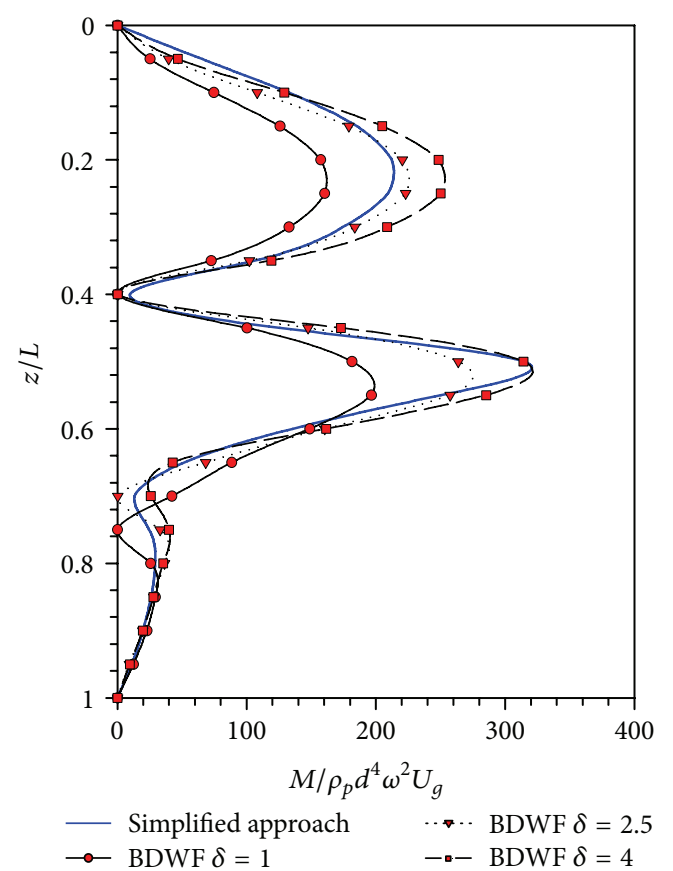

(a)

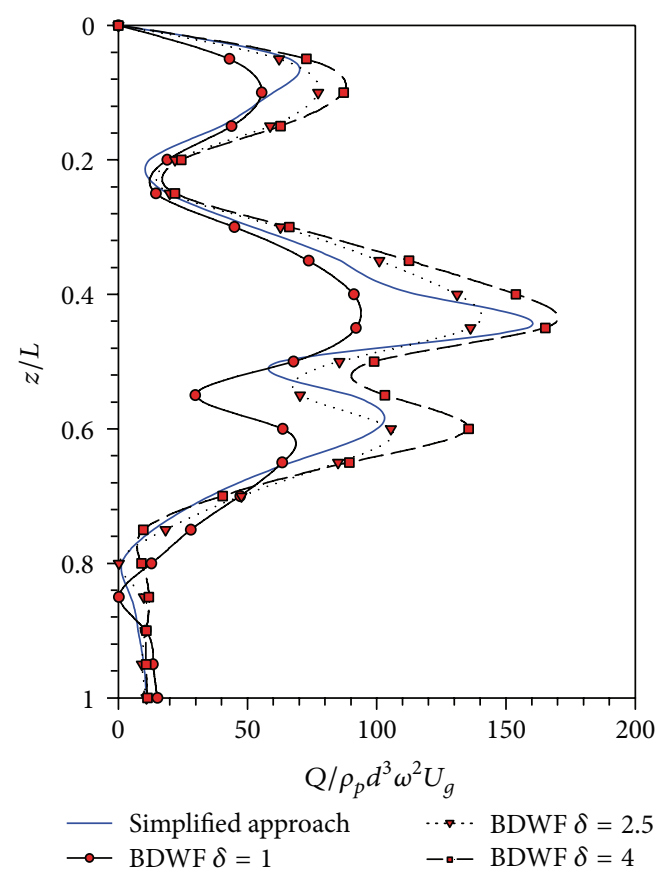

(b)

FIGURE 5: Comparison of amplitude of (a) bending moment profile and (b) shear force profile for two-layer soil $\left(\right.$ Case $12: V_{b} / V_{a}=1.73$, $E_{p} / E_{a}=500, H_{a} / H_{b}=1$, and $\left.L / d=20\right)$.

kinematic pile bending and shear force profiles are slightly sensitive to the value $\delta$. At $\delta=2.5$, the distribution profiles of pile moment and shear force agree with each other between the simplified results and the BDWF solution, although the maximum moment of the simplified method is $17.2 \%$ larger than the BDWF solution.

Figure 6 provides the corresponding amplitude spectrum of maximum kinematic pile bending moment in the twolayer soil, owing to variation in the frequency ratio $\omega / \omega_{1}$, among the FE, the BDWF, and the simplified approaches. It shows a consistent trend of variation in bending moment among various approaches.
3.2.2. Kinematic Response of Pile Head. Kinematic responses are obtained in form of the ratio of the amplitudes of pilehead displacement $\mathbf{u}_{p}(0)$ over the excitation motion $\mathbf{u}_{g}$ or the ratio of the head displacement $\mathbf{u}_{p}(0)$ over the free field surface displacement $\mathbf{u}_{e}(0)[17,26,39]$. The responses for the free-head pile are plotted in Figure 7 for a spectrum of the frequency ratio $\omega / \omega_{1}$. The good agreement of the factors $\mathbf{u}_{p}(0) / \mathbf{u}_{g}$ and $\mathbf{u}_{p}(0) / \mathbf{u}_{e}(0)$ among the simplified approach, the FE method, and the BDWF solution has been attributed to the predominant effect of the free field soil displacement.

As for fixed-head piles, equally successful prediction is seen in Figure 8, concerning the kinematic response of pile to 


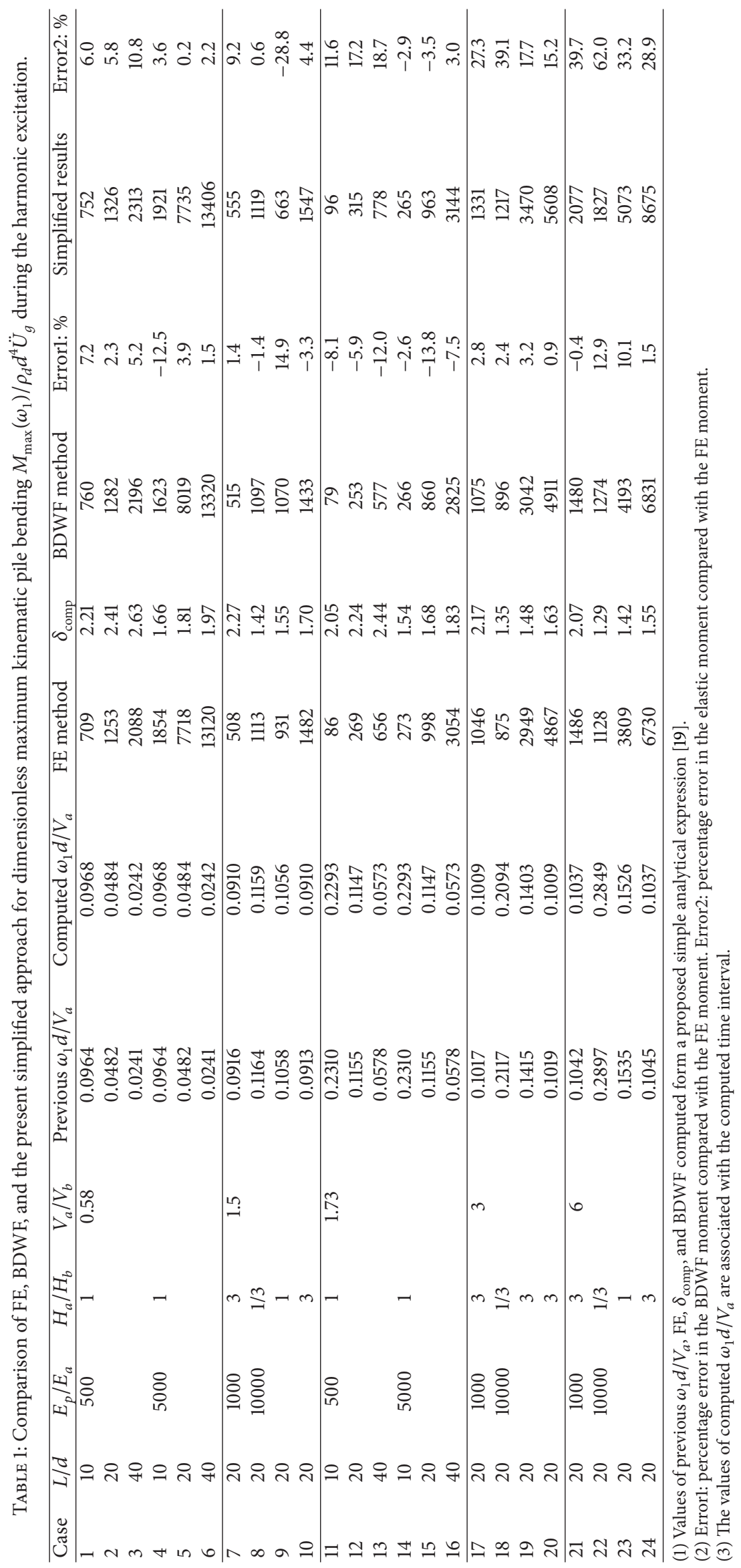




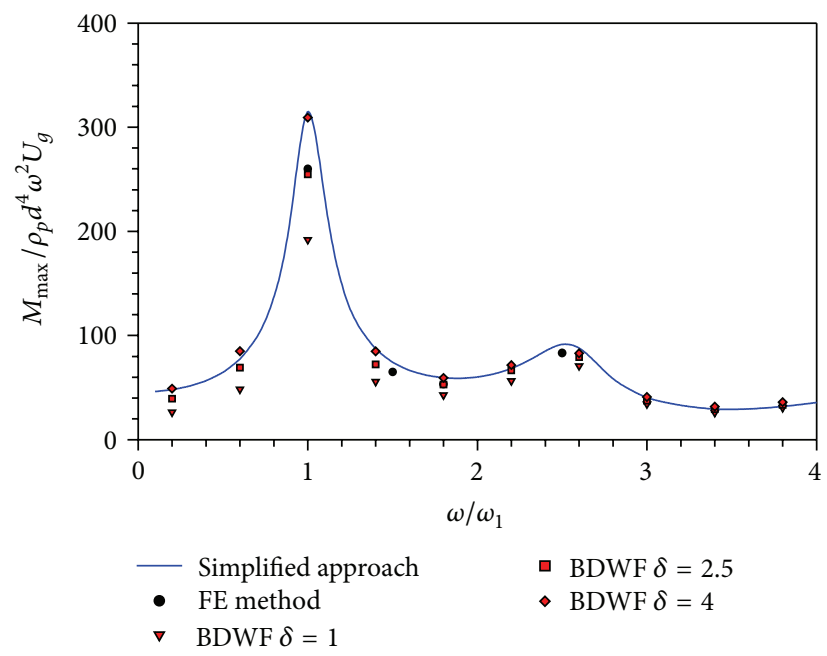

FIGURE 6: Comparison of maximum kinematic pile bending amplitude between FE, BDWF, and simplified approaches in a two-layer soil (Case 12: $V_{b} / V_{a}=1.73, E_{p} / E_{a}=500, H_{a} / H_{b}=1$, and $L / d=20$ ).

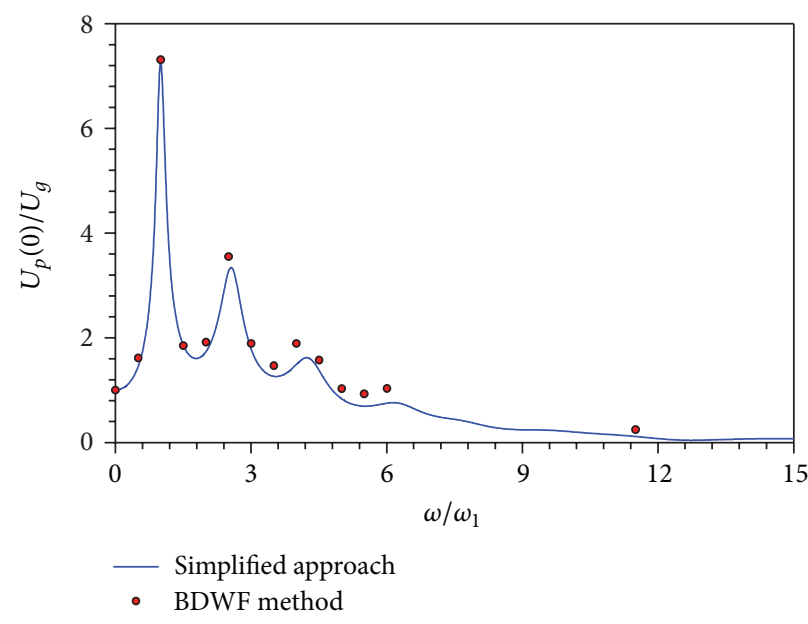

(a) Amplitude of pile-top deflection

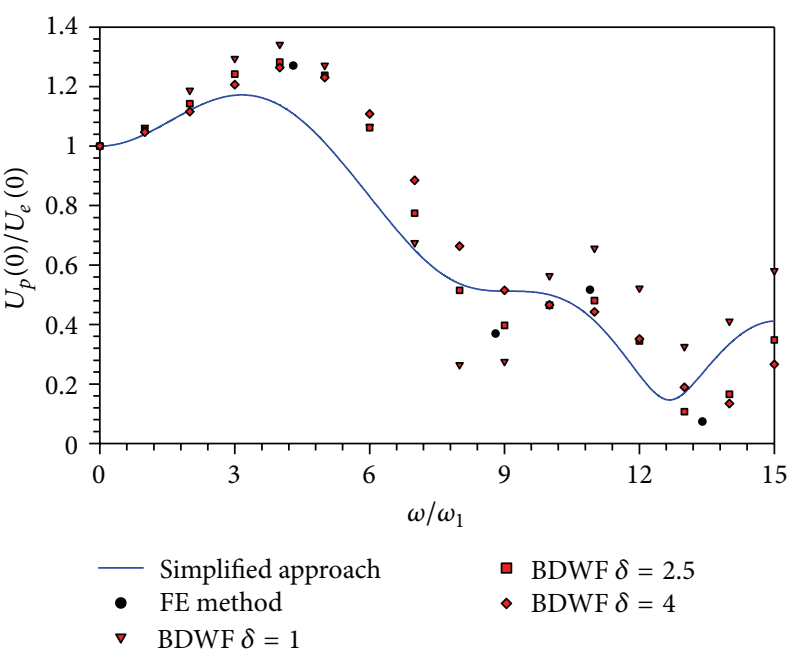

(b) Pile-head to ground-surface displacements

Figure 7: Normalized kinematic response of pile head to excitation among FE, BDWF, and simplified methods in a two-layer soil (Case 12: $V_{b} / V_{a}=1.73, E_{p} / E_{a}=500, H_{a} / H_{b}=1$, and $L / d=20$ ).

soil displacement $\mathbf{u}_{p}(0) / \mathbf{u}_{e}(0)$ among the simplified method, the rigorous boundary integral method (Fan et al. [18]), and the BDWF (Makris and Gazetas [26]). Nevertheless, the current approach offers slightly larger ratio for $E_{p} / E_{s}=1000$ than the other two solutions at high frequencies.

\section{Application under Seismic Excitation}

4.1. Seismic Motion and Case Model. The harmonic steady state is rarely seen in a practical engineering design. Kinematic seismic response of a pile should be tailored to cater for the transient excitation [19] owing to earthquake shaking, as is noted in dynamic analysis involving nonlinear pilesoil interaction. A large soil resistance in certain depth may render the nonlinear kinematic pile bending (e.g., caused by
SH wave) insignificant compared to pile-head inertial excitation. In addition, previous study [13] does not allow either a detrimental or a beneficial effect on kinematic pile bending to be concluded due to non-linear site response. Consequently, the validity of the simplified method is examined herein for elastic pile and soil.

The performance of the simplified approach for the transient response is examined for six typical seismic accelerograms (see Table 2), which include 4 actual records selected from ground motion database of the Pacific Earthquake Engineering Research Center (PEER) [41] and 2 artificial motions used in seismic design of a typical site in Shanghai (China). The acceleration time histories for seismic events are plotted in Figure 9 and the associated acceleration response spectra are provided in Figure 10. 


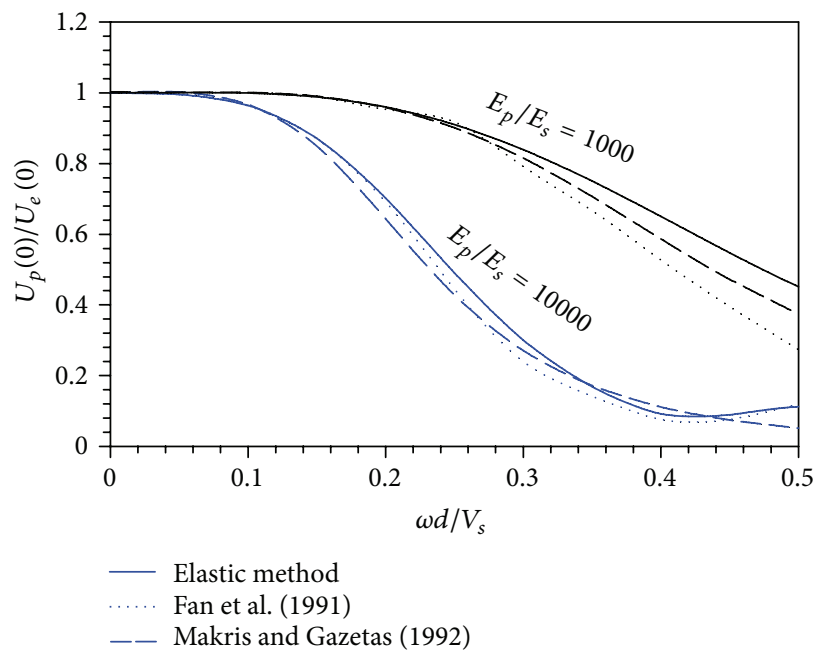

FigURE 8: Normalized response of a fixed-head pile among simplified approach, BDWF [26], and rigorous results [18] $\left(L / d=20, \rho_{s} / \rho_{p}=0.7\right.$, $\beta_{s}=0.05$, and $\mu_{s}=0.4$ ).
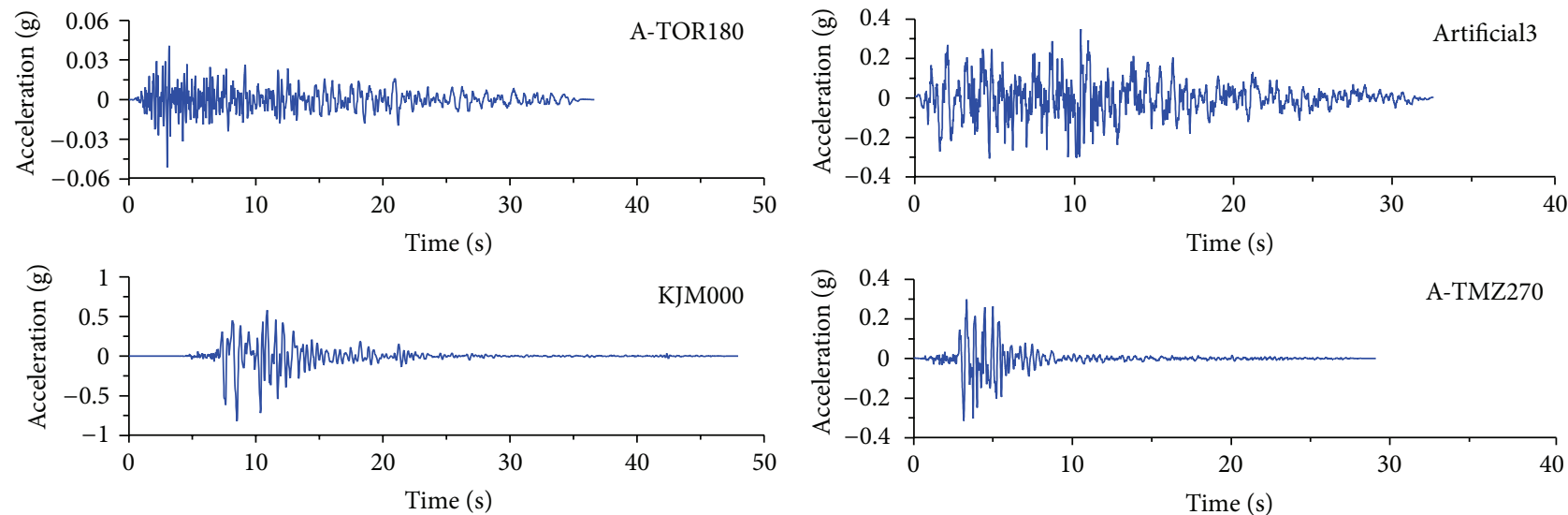

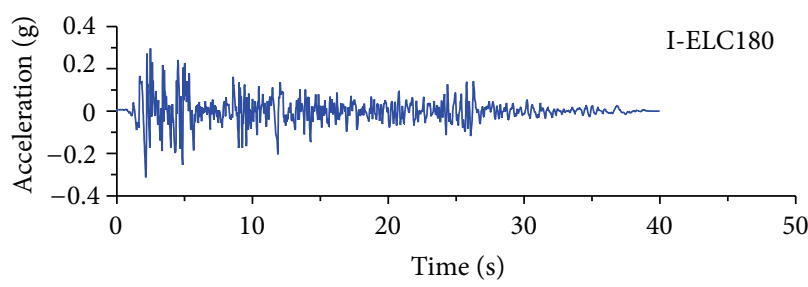

(a)

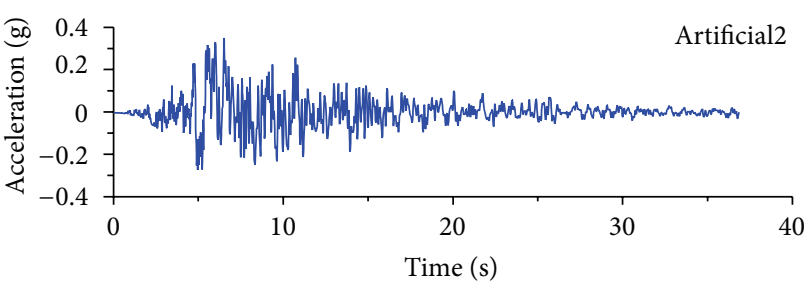

(b)

FIGURE 9: Acceleration time history of the input motions at the bedrock roof.

TABLE 2: Ground motions employed in the parametric analysis.

\begin{tabular}{|c|c|c|c|c|c|}
\hline Earthquake & Record label & $M_{w}$ & PGA (g) & $T_{p}(\mathrm{sec})$ & $T_{m}(\mathrm{sec})$ \\
\hline Whittier Narrows 1987/10/01 & A-TOR180 & 6.0 & 0.05 & 0.24 & 0.42 \\
\hline Kobe 1995/01/16 & KJM000 & 6.9 & 0.82 & 0.34 & 0.64 \\
\hline Imperial Valley 1940/05/19 & I-ELC180 & 7.0 & 0.31 & 0.46 & 0.53 \\
\hline ShangHai3-Elcentrol (IV Site) & Artificial3 & & 0.35 & 0.58 & 0.82 \\
\hline Friuli 1976/05/06 & A-TMZ270 & 6.5 & 0.32 & 0.64 & 0.50 \\
\hline ShangHai2 (IV Site) & Artificial2 & & 0.35 & 0.72 & 0.75 \\
\hline
\end{tabular}

$T_{p}$ : predominant period and $T_{m}$ : mean period. 


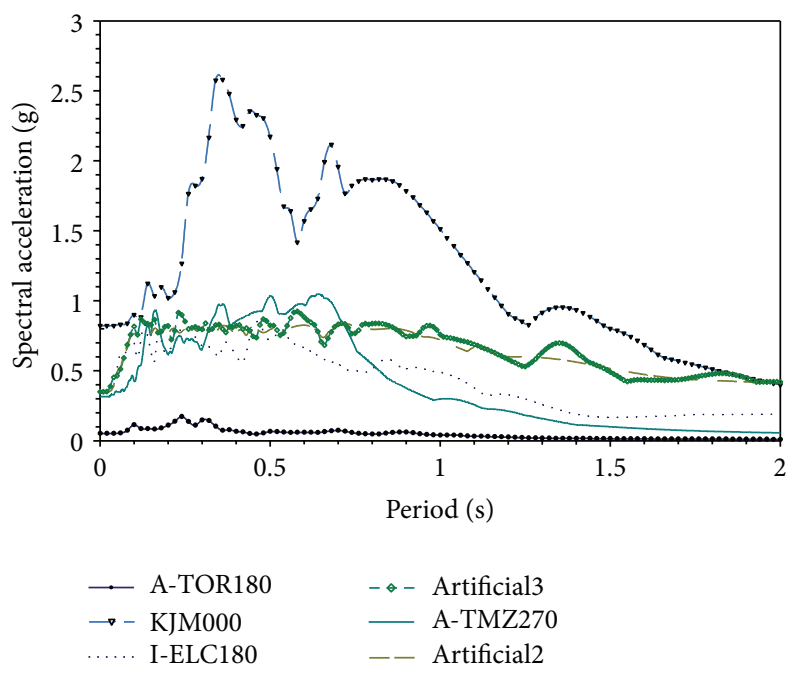

FIGURE 10: Acceleration response spectra (5\% damping) of the input motions.

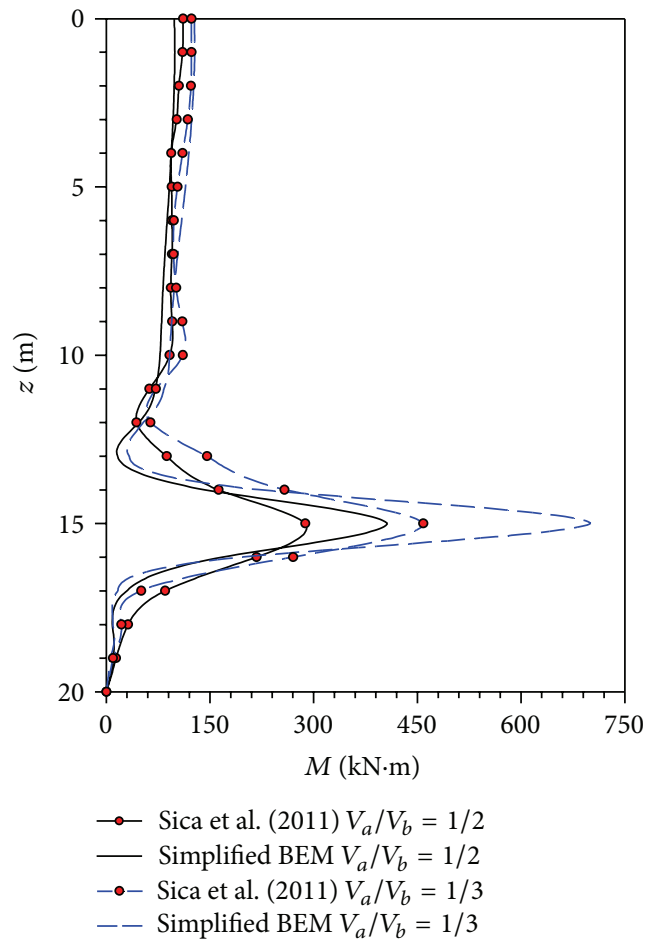

FIGURE 11: Validation of the proposed procedure under the input motion A-TMZ270 $\left(L / d=33.3, H_{a} / H_{b}=1, E_{p} / E_{a}=470, \rho_{s} / \rho_{p}=0.76\right.$, and $\left.\mu_{a}=\mu_{b}=0.4\right)$.

4.2. Parametric Investigation. The parametric analysis is again conducted for the pile-soil system shown in Figure 1, with the following profile parameters: bedrock located at $H=$ $30 \mathrm{~m}$, density of either soil layer $=1900 \mathrm{~kg} / \mathrm{m}^{3}$, Poisson's ratio $=0.4$, soil damping $=5 \%$, pile density $=2500 \mathrm{~kg} / \mathrm{m}^{3}$, and pileto-soil stiffness ratio $E_{p} / E_{a}=1000$. The shear wave velocity is $100 \mathrm{~m} / \mathrm{s}$ for the upper soil layer, $150 \mathrm{~m} / \mathrm{s}$ for the lower layer, and $1000 \mathrm{~m} / \mathrm{s}$ for the bedrock, respectively. The input signals by Sica et al. [31] were scaled in amplitude to a peak acceleration of $0.35 \mathrm{~g}$ [31]. Figure 11 shows the comparison of kinematic pile bending between the simplified proposed approach and the BDWF formulation [31]. A good agreement in the predicted bending moment is evident between the simplified method and the BDWF solution, but for the large difference in the peak bending moment around the layer interface and at a shear wave velocity ratio $V_{a} / V_{b}$ of $1 / 3$.

Figure 12 shows the pile-diameter contrast on kinematic bending moment under the six input motions. The ratio of soil layer thickness $H_{a} / H_{b}$ is 1 , the pile is $20 \mathrm{~m}$ in length and $0.6,0.9$, or $1.2 \mathrm{~m}$ in diameter, and the head is 

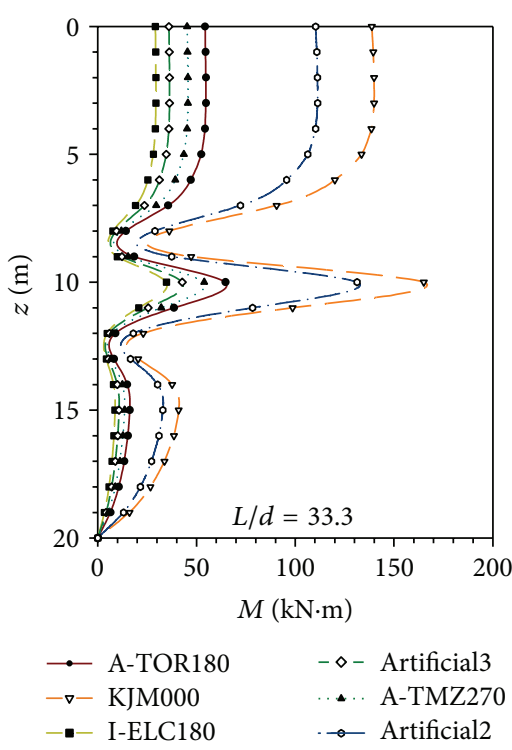

(a)
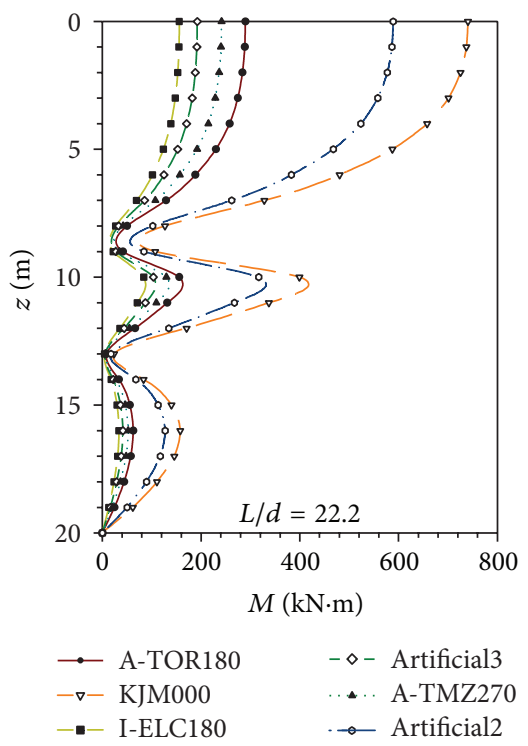

(b)

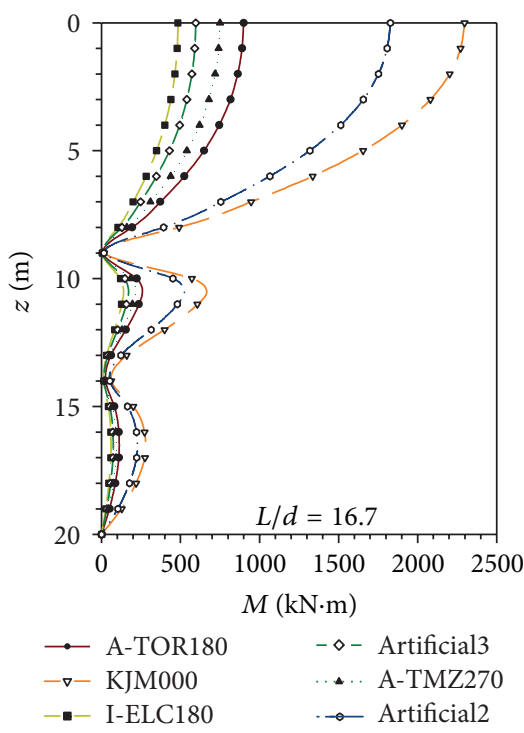

(c)

FIGURE 12: Pile diameters contrast on kinematic pile bending moment under different input motions.

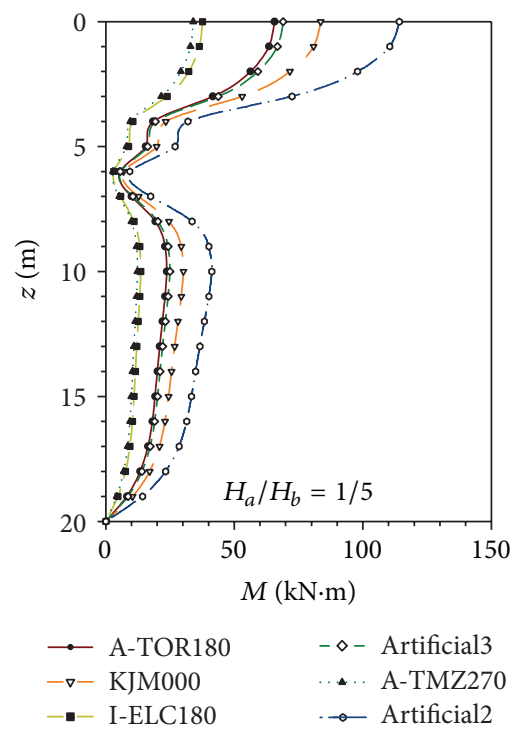

(a)

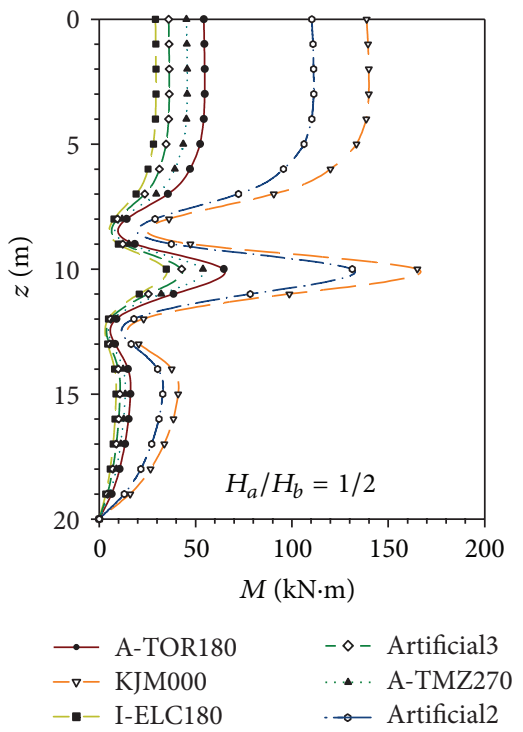

(b)

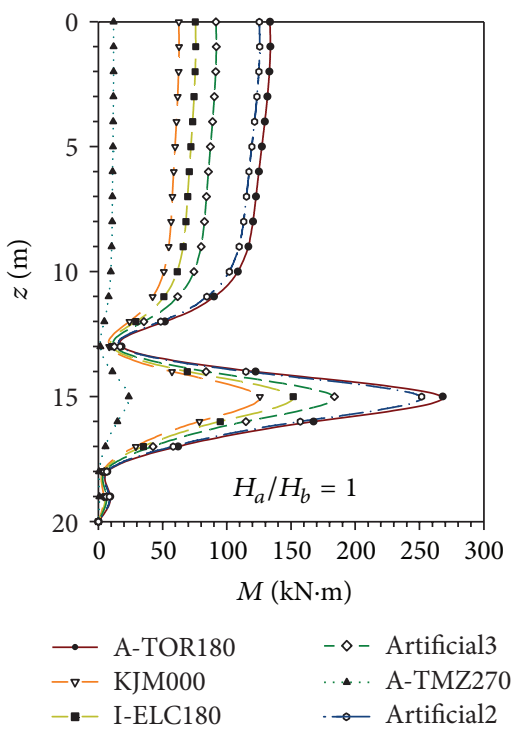

(c)

FiguRE 13: Depths of the interface between the two layers contrast on kinematic pile bending moment under different input motions.

constrained against rotation (fixed head). The figure indicates that small-diameter piles accommodate more easily to seismically induced soil deformations than lager-diameter piles. Kinematic bending moments at the pile head and the interface of soil layers are nearly proportional to the diameters. This will reduce the safety of pile head, although it does not necessarily increase or reduce the seismic safety of the pile body (depending on the circumstances), as is discussed previously $[10,14]$.

Figure 13 presents the bending moment profiles owing to variation in the depths of the interface of the two layers under the six input motions. They were obtained for a fixed head pile (20 $\mathrm{m}$ in length, $0.6 \mathrm{~m}$ in diameter) embedded in a soil with a layer interface located at a depth of 5,10 , or $15 \mathrm{~m}$, respectively. An increase in depth of the interface renders increase in the peak value of kinematic pile bending but has a negligible impact on the kinematic bending moment at the pile head. This preliminary analysis suggests the simplified approach has the potential in modeling kinematic seismic response of piles during the earthquake.

\section{Conclusion and Discussions}

A simple approach is formulated to predict the elastic, kinematic pile bending during harmonic or transient excitation. The approach employs a circular pile (rather than a simplified 
thin strip). The kinematic response of a pile embedded in two-layer soil is resolved in the frequency domain owing to specified soil displacement field. The simplified approach is generally valid to nonhomogeneous soil problems, in light of the good comparison with the dynamic FE method and BDWF solution. The main conclusions from the study are as follows.

The simplified method employs the soil-displacementinfluence coefficients $\mathbf{I}_{s}$ to consider the pile-soil interaction (resembling the spring constant $k_{x}$ in the BDWF). It provides conservative estimation of maximum kinematic bending moments at soil-layer interface (with a sharper stiffness contrast) despite an adequate accuracy in general. The accuracy may be improved by incorporating the interaction of soil into the soil-displacement-influence coefficients $\mathbf{I}_{s}$ for such cases with $V_{b} / V_{a}<3$.

The parametric studies during the seismic excitation show the impact of pile diameters and depths of the interface of two layers and demonstrate the simplified approach comparing well with published results in gaining kinematic pile bending during the earthquake.

The formulated simple method is intended for elastic soil, elastic pressure on pile-soil interface, and elastic seismic response of the free field soil, for which a judicious choice of elastic modulus of the soil is required. The method may be extended to elastoplastic case though introducing a similar technology as cut-off method $[28,33]$ in the current procedure.

\section{Acknowledgments}

The work reported herein was supported by the National Natural Science Foundation of China (Grants nos. 41172246, 90915011), the National Key Basic Research Program of China (Grant no. 2013CB036304), and the Fundamental Research Funds for the Central Universities, Tongji University. The above financial support is gratefully acknowledged.

\section{References}

[1] W. D. L. Finn, "A study of piles during earthquakes: issues of design and analysis," Bulletin of Earthquake Engineering, vol. 3, no. 2, pp. 141-234, 2005.

[2] S. Nikolaou, G. Mylonakis, G. Gazetas, and T. Tazoh, "Kinematic pile bending during earthquakes: analysis and field measurements," Geotechnique, vol. 51, no. 5, pp. 425-440, 2001.

[3] G. Mylonakis, "Simplified model for seismic pile bending at soil layer interfaces," Soils and Foundations, vol. 41, no. 4, pp. 47-58, 2001.

[4] B. A. Bradley, M. Cubrinovski, and J. J. M. Haskell, "Probabilistic pseudo-static analysis of pile foundations in liquefiable soils," Soil Dynamics and Earthquake Engineering, vol. 31, no. 10, pp. 1414-1425, 2011.

[5] J. P. Stewart, R. B. Seed, and G. L. Fenves, "Seismic soil-structure interaction in buildings. II: empirical findings," Journal of Geotechnical and Geoenvironmental Engineering, vol. 125, no. 1, pp. 38-48, 1999.

[6] T. Tazoh, K. Shimizu, and T. Wakahara, "Seismic observations and analysis of grouped piles," in Dynamic Response of Pile
Foundations-Experiment, Analysis and Observation (GSP 11), pp. 1-20, 1987.

[7] K. Tokimatsu, "Behaviour and design of pile foundations subjected to earthquakes," in Proceedings of the 12th Asian Regional Conference on Soil Mechanics and Geotechnical Engineering, vol. 1 and 2, Singapore, 2003.

[8] K. Tokimatsu, H. Suzuki, and M. Sato, "Effects of inertial and kinematic interaction on seismic behavior of pile with embedded foundation," Soil Dynamics and Earthquake Engineering, vol. 25, no. 7-10, pp. 753-762, 2005.

[9] R. M. S. Maiorano, L. De Sanctis, S. Aversa, and A. Mandolini, "Kinematic response analysis of piled foundations under seismic excitation," Canadian Geotechnical Journal, vol. 46, no. 5, pp. 571-584, 2009.

[10] F. Dezi, S. Carbonari, and G. Leoni, "Kinematic bending moments in pile foundations," Soil Dynamics and Earthquake Engineering, vol. 30, no. 3, pp. 119-132, 2010.

[11] L. de Sanctis, R. M. S. Maiorano, and S. Aversa, "A method for assessing kinematic bending moments at the pile head," Earthquake Engineering \& Structural Dynamics, vol. 39, no. 10, pp. 1133-1154, 2010.

[12] R. Di Laora, G. Mylonakis, and A. Mandolini, "Pile-head kinematic bending in layered soil," Earthquake Engineering \& Structural Dynamics, vol. 42, pp. 319-337, 2013.

[13] S. Sica, G. Mylonakis, and A. L. Simonelli, "Strain effects on kinematic pile bending in layered soil," Soil Dynamics and Earthquake Engineering, vol. 49, pp. 231-242, 2013.

[14] R. Di Laora, A. Mandolini, and G. Mylonakis, "Insight on kinematic bending of flexible piles in layered soil," Soil Dynamics and Earthquake Engineering, vol. 43, pp. 309-322, 2012.

[15] M. Saitoh, "Fixed-head pile bending by kinematic interaction and criteria for its minimization at optimal pile radius," Journal of Geotechnical and Geoenvironmental Engineering, vol. 131, no. 10, pp. 1243-1251, 2005.

[16] R. Di Laora and A. Mandolini, "Some remarks about Eurocode and Italian code about piled foundations in seismic area," in Presented at the ERTC-12 Workshop on Evaluation of EC8, Athens, Greece, 2011.

[17] A. M. Kaynia and E. Kausel, "Dynamic stiffness and seismic response of pile groups," Research Report R82-03, Massachusetts Institute of Technology, Cambridge, Mass, USA, 1982.

[18] K. Fan, G. Gazetas, A. Kaynia, E. Kausel, and S. Ahmad, "Kinematic seismic response of single piles and pile groups," Journal of Geotechnical Engineering, vol. 117, no. 12, pp. 18601879, 1991.

[19] M. Kavvadas and G. Gazetas, "Kinematic seismic response and bending of free-head piles in layered soil," Geotechnique, vol. 43, no. 2, pp. 207-222, 1993.

[20] M. H. El Naggar and M. Novak, "Nonlinear analysis for dynamic lateral pile response," Soil Dynamics and Earthquake Engineering, vol. 15, no. 4, pp. 233-244, 1996.

[21] G. Wu and W. D. L. Finn, "Dynamic nonlinear analysis of pile foundations using finite element method in the time domain," Canadian Geotechnical Journal, vol. 34, no. 1, pp. 44-52, 1997.

[22] B. K. Maheshwari, K. Z. Truman, M. H. El Naggar, and P. L. Gould, "Three-dimensional nonlinear analysis for seismic soil-pile-structure interaction," Soil Dynamics and Earthquake Engineering, vol. 24, no. 4, pp. 343-356, 2004.

[23] F. Dezi, S. Carbonari, and G. Leoni, "A model for the 3D kinematic interaction analysis of pile groups in layered soils," 
Earthquake Engineering \& Structural Dynamics, vol. 38, no. 11, pp. 1281-1305, 2009.

[24] M. A. Millán and J. Domínguez, "Simplified BEM/FEM model for dynamic analysis of structures on piles and pile groups in viscoelastic and poroelastic soils," Engineering Analysis with Boundary Elements, vol. 33, no. 1, pp. 25-34, 2009.

[25] F. Dezi, S. Carbonari, and G. Leoni, "Static equivalent method for the kinematic interaction analysis of single piles," Soil Dynamics and Earthquake Engineering, vol. 30, no. 8, pp. 679690, 2010.

[26] N. Makris and G. Gazetas, "Dynamic pile-soil-pile interaction. Part II: lateral and seismic response," Earthquake Engineering \& Structural Dynamics, vol. 21, no. 2, pp. 145-162, 1992.

[27] G. Mylonakis, A. Nikolaou, and G. Gazetas, "Soil-pile-bridge seismic interaction: kinematic and inertial effects. Part I: soft soil," Earthquake Engineering \& Structural Dynamics, vol. 26, no. 3, pp. 337-359, 1997.

[28] A. Tabesh and H. G. Poulos, "Pseudostatic approach for seismic analysis of single piles," Journal of Geotechnical and Geoenvironmental Engineering, vol. 127, no. 9, pp. 757-765, 2001.

[29] T. Juirnarongrit and S. A. Ashford, "Soil-pile response to blastinduced lateral spreading. II: analysis and assessment of the p-y method," Journal of Geotechnical and Geoenvironmental Engineering, vol. 132, no. 2, pp. 163-172, 2006.

[30] F. Castelli and M. Maugeri, "Simplified approach for the seismic response of a pile foundation," Journal of Geotechnical and Geoenvironmental Engineering, vol. 135, no. 10, pp. 1440-1451, 2009.

[31] S. Sica, G. Mylonakis, and A. L. Simonelli, "Transient kinematic pile bending in two-layer soil," Soil Dynamics and Earthquake Engineering, vol. 31, no. 7, pp. 891-905, 2011.

[32] H. G. Poulos and E. H. Davis, "Pile foundation analysis and design," 1980.

[33] H. Elahi, M. Moradi, H. G. Poulos, and A. Ghalandarzadeh, "Pseudostatic approach for seismic analysis of pile group," Computers and Geotechnics, vol. 37, no. 1-2, pp. 25-39, 2010.

[34] R. D. Mindlin, "Force at a point in the interior of a semi-infinite solid," Journal of Applied Physics, vol. 7, no. 5, pp. 195-202, 1936.

[35] Y. M. A. Hashash, C. Phillips, and D. R. Groholski, "Recent advances in non-linear site response analysis," in Proceedings of the 5th International Conference in Recent Advances in Geotechnical Eartqhuake Engineering and Soil Dynamics, 2010.

[36] L. F. Shampine, "Vectorized adaptive quadrature in MATLAB," Journal of Computational and Applied Mathematics, vol. 211, no. 2, pp. 131-140, 2008.

[37] D. Park and Y. M. A. Hashash, "Soil damping formulation in nonlinear time domain site response analysis," Journal of Earthquake Engineering, vol. 8, no. 2, pp. 249-274, 2004.

[38] G. A. Ordonez, "SHAKE2000: a computer program for the 1D analysis of geotechnical earthquake engineering problems," 2004.

[39] G. Wu and W. D. L. Finn, "Dynamic elastic analysis of pile foundations using finite element method in the frequency domain," Canadian Geotechnical Journal, vol. 34, no. 1, pp. 3443, 1997.

[40] R. W. Boulanger, C. J. Curras, B. L. Kutter, D. W. Wilson, and A. Abghari, "Seismic soil-pile-structure interaction experiments and analyses," Journal of Geotechnical and Geoenvironmental Engineering, vol. 125, no. 9, pp. 750-759, 1999.

[41] P. G. Motion, "Pacific earthquake engineering research center," Tech. Rep., University of California, Berkeley, Berkeley, Calif, USA, 2008. 


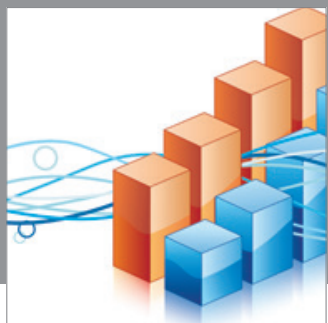

Advances in

Operations Research

mansans

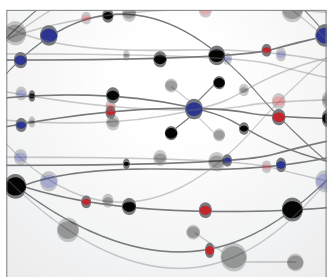

The Scientific World Journal
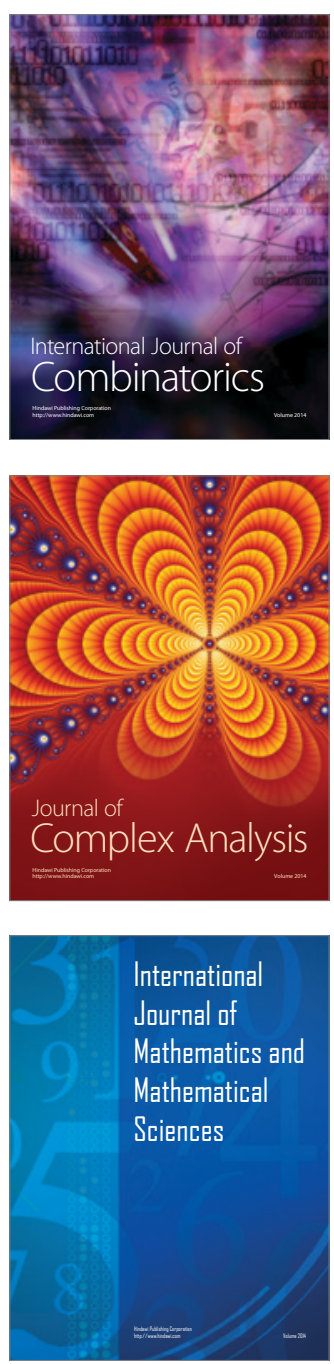
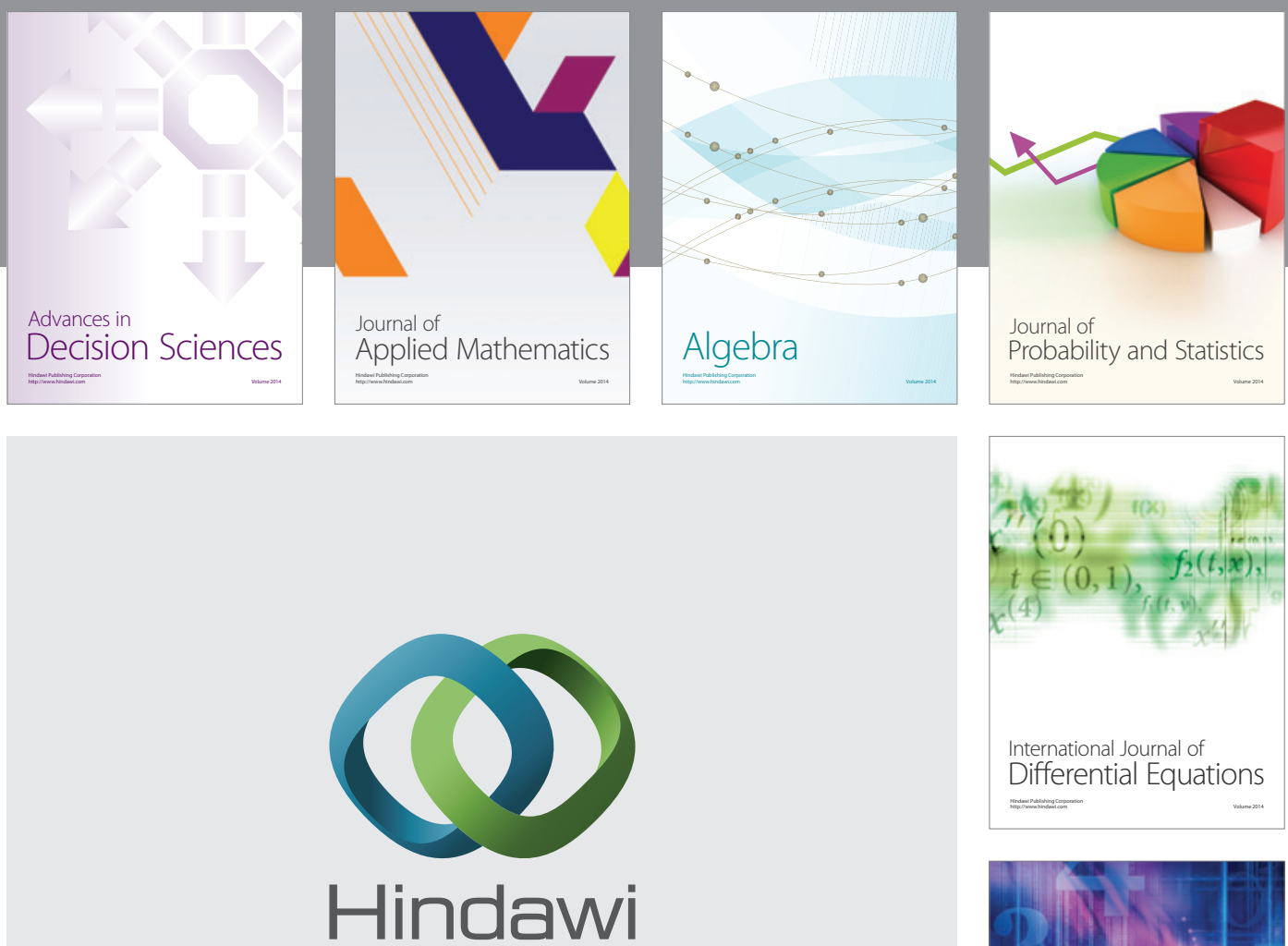

Submit your manuscripts at http://www.hindawi.com
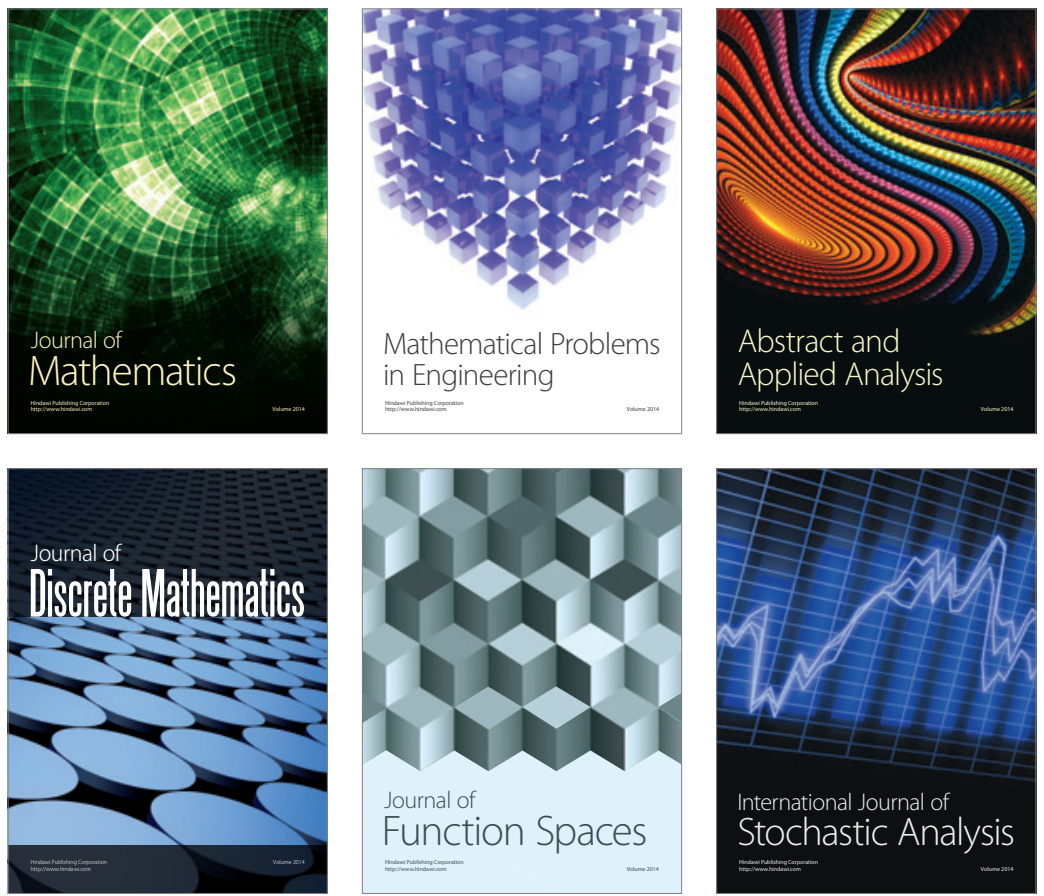

Journal of

Function Spaces

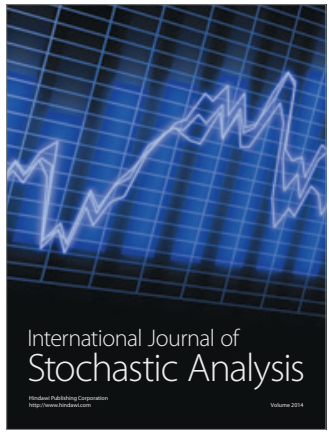

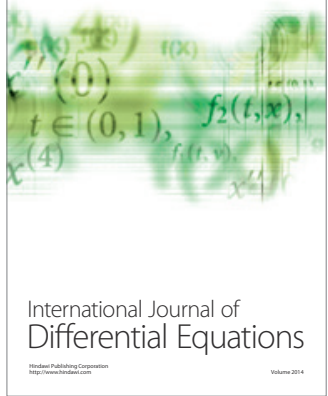
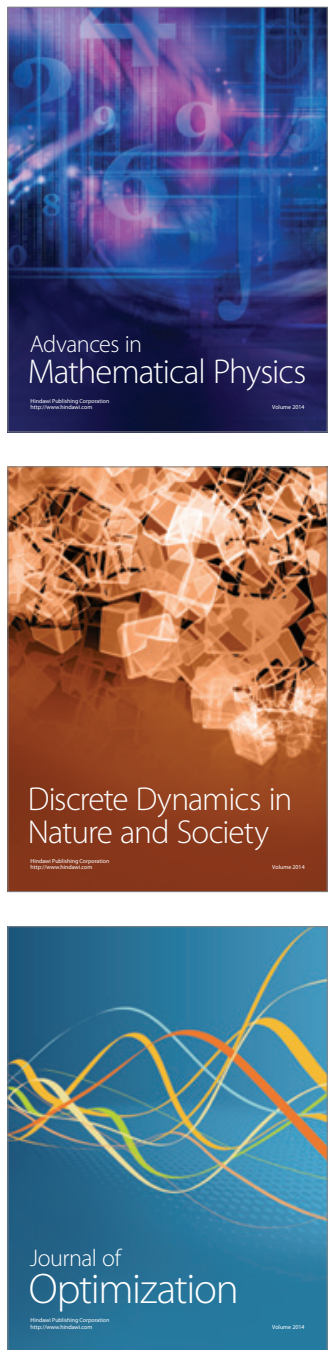